\title{
Uptake of photofrin II, a photosensitizer used in photodynamic therapy, by tumour cells in vitro
}

\author{
Agnieszka Chwiłkowska ${ }^{1 凶}$, Jolanta Saczko ${ }^{1}$, Teresa Modrzycka ${ }^{2}$, Anna \\ Marcinkowska $^{1}$, Anna Malarska ${ }^{1}$, Julita Bielewicz ${ }^{1}$, Dorota Patalas ${ }^{1}$ and \\ Teresa Banaś ${ }^{1}$ \\ ${ }^{1}$ Department of Medical Biochemistry, Wroctaw Medical University, Wroctaw, Poland; \\ ${ }^{2}$ Department of Biophysics, Wroctaw Medical University, Wroctaw, Poland
}

Received: 14 October, 2002; revised: 10 April, 2003; accepted: 08 May, 2003

Key words: photodynamic therapy, photofrin II, fluorescence spectra

Photosensitizing dyes are used in fluorescence diagnostics and photodynamic therapy (PDT). These usually hematoporphyrin derivatives (HpD) accumulate preferentially within neoplastic tissues. $\mathrm{HpD}$ is a mixture of ether and ester linked porphyrins. Its partially purified form is known under the commercial name of photofrin II (PII).

PII emission spectra were studied in a hydrophilic (PBS) and a lipophilic (PC liposomes) environment. Red shift was observed in their emission maxima from 615 $\mathrm{nm}$ in buffer solution to $635 \mathrm{~nm}$ in lipid. Identical red shift was obtained when the intracellular fluorescence of two cancer cell lines, MCF 7 and Jurkat, incubated with PII was investigated. Thus, intramembrane localization of PII may be suggested. As determined from the total fluorescence intensity, the uptake of PII was only slightly higher for Jurkat than for MCF 7 cells. Nevertheless the kinetics of the uptake was found to be different for both cell lines.

Photodynamic therapy (PDT) is an emerging treatment for a variety of conditions, but particularly for cancer and for wet age-related macular degeneration. PDT is a cancer treatment involving incorporation of photosensitizing molecules into malignant tumours and their activation with visible light. In general porphyrin-type dyes have been employed as photosensitiers in cancer phototherapy because of their properties: high singlet oxygen quantum yields, apparent lack of dark toxicity, and absorption in the red region

\footnotetext{
${ }^{\otimes}$ Agnieszka Chwiłkowska, Department of Medical Biochemistry, Wrocław Medical University, T. Chałubińskiego 10, 50-368 Wrocław, Poland; phone: (48 71) 784 1375; fax: (48 71) 784 0085; e-mail: maria@bioch.am.wroc.pl

Abbreviations: EYPC, L- $\alpha$-phosphatidylcholine; FBS, fetal bovine serum; HDLs, high density lipoproteins; HpD, hematoporphyrin derivatives; MEM, minimum essential medicum; LDLs, low density lipoproteins; PBS, phosphate-buffered saline; PDT, photodynamic therapy; PII, photofrin II.
} 
(Ochsner, 1997). HpD is an unstable mixture of porphyrin monomers and oligomers joined by ether and ester linkages. The antitumour activity basically resides in the covalentlylinked oligomeric fraction, and therefore in the commercial preparations the less active monomeric fraction is removed using HPLC or gel permeation chromatography (Sternberg et al. 1998). This more purified version called PII, was the first photosensitizer employed in PDT. PII was authorized for use against certain types of bladder tumour in Canada, U.S.A., Japan, and some European countries.

Upon photoactivation, PII may produce high quantum yield of singlet oxygen and/or superoxide anions, and even semiquinone radicals (Foster et al., 1991; Kriska et al., 1995; Fernandez et al., 1997). Once generated, each one of these biochemical species may cause cell injury (Furuse et al., 1993). Tumours selectively take up PII, but the process of photosensitizer localisation, which favours tumour accumulation, is not really understood. This effect is partly related to the high lipophilicity of PII (Ricchelli, 1995). In in vivo treatments, after intravenous administration of hydrophobic sensitizers, the compounds are, in general, strongly bound to lipoproteins, high density lipoproteins (HDLs) and low density lipoproteins (LDLs), distributed with the blood system and transported to the malignant tissue with distinct selectivity (Gèze et al., 1994; Byrne et al., 1990). It is well accepted today that the tumour selectivity increases with the lipophilic character of the sensitizing agent. An examination of the components of PII reveals that the therapeutically active lipophilic fraction consists of a heterogenous and poorly reproducible mixture of different porphyrins with various degrees of oligomerization (from monomers to hexamers) and chemical structures (ether and ester linkages between porphyrin units) (Byrne et al., 1990). In solution these oligomers assume a compact structure with the individual porphyrin rings stacked over one an- other, and the concurrent increase in hydrophobicity leads to enhanced intracellular accumulation (Ochsner, 1997). Differences in the clearance rates of sensitizers between tissues enable one to establish the most appropriate timing of irradiation of neoplastic tissue. The preferred accumulation of lipophilic sensitizers, such as PII, within tumour tissues is in reasonable harmony with the observation that neoplastic cells express a particularly large number of membrane receptors for LDLs (Korbelik, 1993; Biade et al., 1992). In vitro and in vivo studies have clearly demonstrated the role of the LDL receptor pathway in the delivery of lipophilic sensitizers to tumour cells. Following receptor-mediated endocytosis, the sensitizer molecules preferentially accumulate in the lipophilic compartments of tumour cells, including the plasma, mitochondrial, endoplasmic reticulum, nuclear and lysosomal membranes. The purpose of this study was to investigate the kinetics of uptake of two cancer cell lines MCF 7 and Jurkat.

\section{MATERIALS AND METHODS}

Chemicals. PII, MEM, L-glutamine and trypsin were obtained from Sigma, fetal bovine serum (FBS) was purchased from Bio-Whittaker, phosphate-buffered saline (PBS) was obtained from IITD (Wrocław, Poland).

L- $\alpha$-Phosphatidylcholine (EYPC) from egg yolk was purchased from Avanti Polar Lipids Inc. (Alabaster, AL, U.S.A.)

Liposome preparation. Unilamellar EYPC liposomes were obtain by sonication of $1 \mathrm{mM}$ phospholipid suspension in PBS using a UP200s sonicator (Dr. Hilsder GmbH, Berlin, Germany)

Culture cells. The cell model used consisted of breast adenocarcinoma MCF 7 cells and leukaemic T cell lymphoblast Jurkat cells. The cells were allowed to grow in MEM medium supplemented with 10\% FBS and glutamine 
(2 $\mathrm{mM}$ ) in a humidified $\mathrm{CO}_{2}$ atmosphere at $37^{\circ} \mathrm{C}$. MCF 7 cells were adherent to the culture support and detached by trypsinization (trypsin 0.025\%, EDTA 0.02\%).

PII incubation for fluorescence measurement. PII was dissolved according to the manufacturer's recommendations in PBS to obtain a $0.6 \mathrm{mg} / \mathrm{ml}$ stock solution. Cells were incubated for times varying from 2 to $24 \mathrm{~h}$ in the described conditions in the presence of PII (final concentration $30 \mu \mathrm{g} / \mathrm{ml}$ ) in the dark. MCF 7 cells were trypsinized and both cell lines were washed three times with BPS, counted and diluted to the same cell concentration (10 5 cells $/ \mathrm{ml})$.

Fluorescence imaging (spectra). Fluorescence intensity was measured at the excitation wavelength of $410 \mathrm{~nm}$ by using an LB 50B spectrofluorimeter (Perkin-Elmer, Beaconsfield, U.K.). The fluorescence spectra were recorded in the $450-700 \mathrm{~nm}$ range.

\section{RESULTS AND DISCUSSION}

\section{Emission spectra of photofrin II}

In the present study PII emission spectra were obtained in a hydrophilic (PBS) and a lipophilic (PC liposomes) environment (final concentration of PII $3 \mu \mathrm{g} / \mathrm{ml}$ ). It can be seen that upon going from the aqueous solution to the more hydrophobic liposomal environment the drug undergoes a red shift in its emission maxima from $615 \mathrm{~nm}$ to $635 \mathrm{~nm}$. A considerable increase of fluorescence intensity was noticed for the same concentration of PII as the medium hydrophobicity increased (Fig. 1).

An identical shift also occurs in the measurement of emission of PII taken up by MCF 7 and Jurkat cells. This suggests intramembrane localization of PII (Fig. 2).

This red shift indicates that the photosensitizer incorporated into cell membranes and this led to the change in its spectral properties. The subcellular dye localisation is the key factor in PDT because it determines the site of the first cell damage after irradiation. The emission fluorescence spectrum of PII was investigated by Candide et al. (1986). They observed that addition of LDL to the solution increased the intensity and induced a

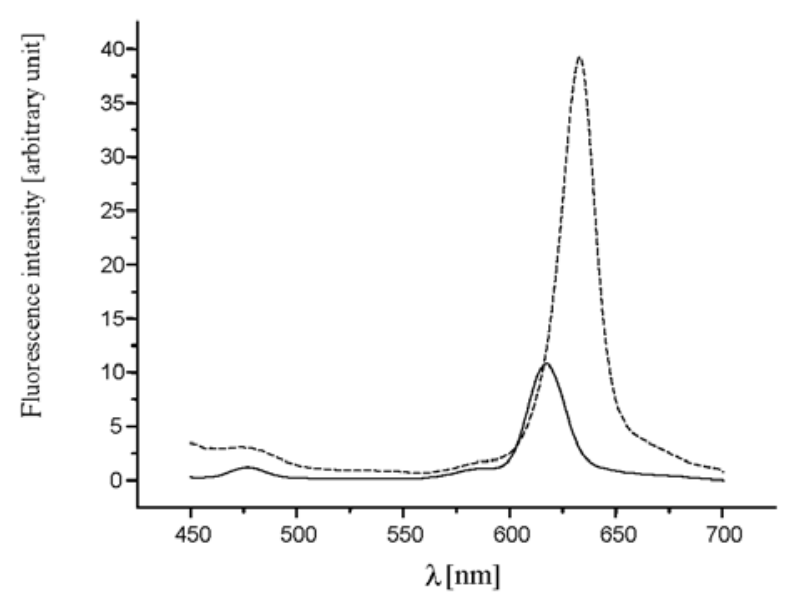

Figure 1. Fluorescence spectra of PII $(3 \mu \mathrm{g} / \mathrm{ml})$ in PBS buffer ( - ) and in EYPC liposomes (- - -) at excitation wavelength of $410 \mathrm{~nm}$.

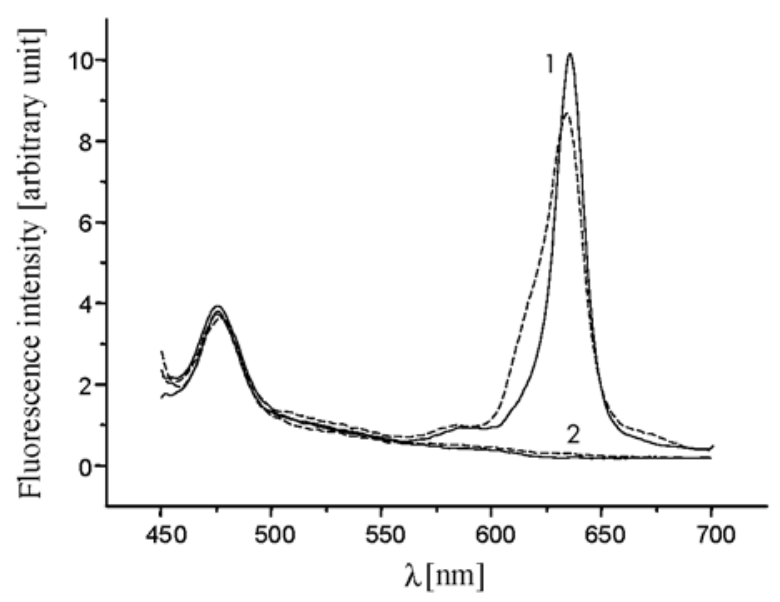

Figure 2. Fluorescence emission spectra at excitation wavelength of $410 \mathrm{~nm}$ from MCF 7 (- - -) and Jurkat (—) cells incubated with PII ( $(30 \mu \mathrm{g} / \mathrm{ml})$ for $5 \mathrm{~h}$ (1) and without photosensitizer (2).

red shift of the emission maximum from 613 $\mathrm{nm}$ to $627 \mathrm{~nm}$.

\section{Comparative photofrin II uptake into MCF 7 and Jurkat cells}

PII uptake was determined by studying fluorescence emission of the drug after various in- 
cubation periods using fluorescence spectroscopy. The fluorescence emission from the cells incubated with PII ( $30 \mu \mathrm{g} / \mathrm{ml})$ appeared as a band with a peak at $635 \mathrm{~nm}$ (Fig. 2). The amount of PII uptake, as determined from the total fluorescence intensity, was found for Jurkat cells to be slightly higher than for MCF 7 cells but the kinetics of the accumulation appeared quite different. Differences in the rate of dye uptake and efflux were observed. For Jurkat cells absorption of the dye reached the maximum within $3 \mathrm{~h}$ and for MCF 7 cells the fluorescence rose more slowly and was maximal after $24 \mathrm{~h}$ (Fig. 3).

Protoporphyrin and hematoporphyrin have been demonstrated to bind to albumin and lipoproteins, mainly LDLs and HDLs. LDL uptake by cells is achieved by receptor-mediated endocytosis which results in LDL-component ference of the photosensitizer with LDL recognition by the specific receptors. The cells were induced in a medium containing lipoprotein-deficient serum to achieve overexpression of LDL receptors. The hematoporphyrin-LDL complex was accumulated by human HT1080 fibroblasts mainly through high affinity LDL-receptors. The uptake of the LDL-delivered hematoporphyrin was about 4-fold higher in HT1080 cells stimulated for maximal expression of LDL receptors as compared with non-stimulated cells but the same complexes are taken up by stimulated and non-stimulated $4 \mathrm{R}$ rat fibroblasts with a similar efficiency (Polo et al., 2002).

Therefore not only induction of LDL-receptors changes the uptake of the photosensitizer by the cell but also the differences in cell morphology influence the rate of PII up-

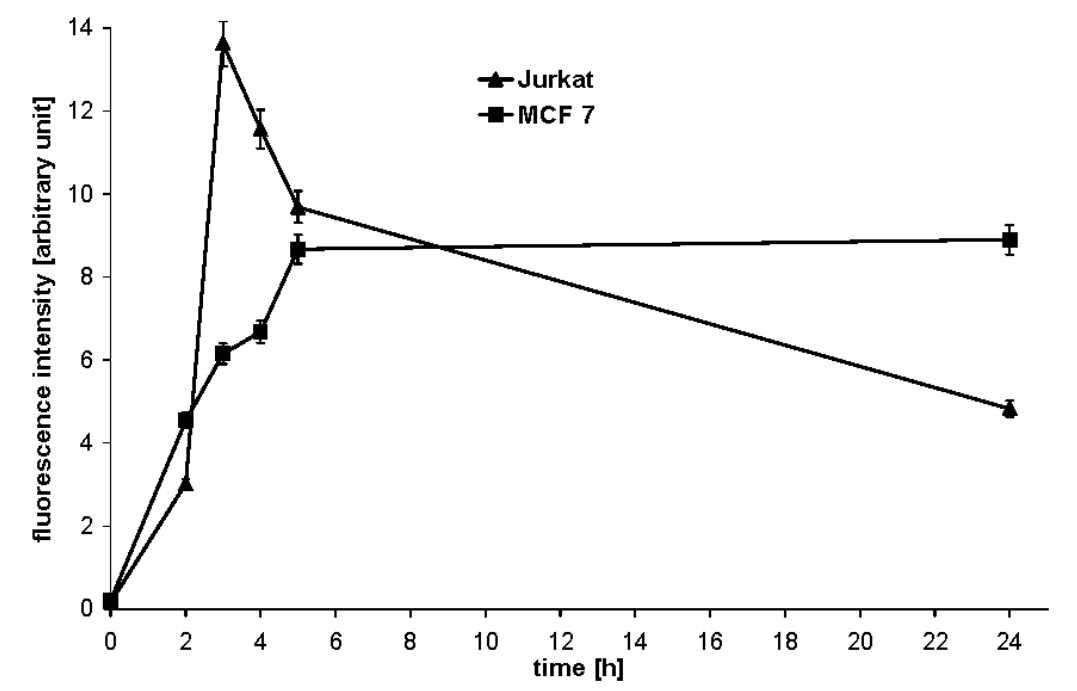

Figure 3. PII uptake (incubation concentration, $30 \mu \mathrm{g} / \mathrm{ml}$ ) by MCF 7 and Jurkat cells.

Cells were incubated for times varying from 2 to $24 \mathrm{~h}$ in the presence of PII (incubation concentration, 30 $\mu \mathrm{g} / \mathrm{ml})$ in the dark.

delivery to the cytosomal compartment. Our results indicate that MCF 7 and Jurkat cells may differ in membrane composition or LDL receptor presentation which in consequence leads to different distribution of the dyes in the cells.

Photosensitizer uptake has been investigated in other studies. Reduction of the LDL-receptor number by preincubation of fibroblasts in a medium supplemented with lipoproteins resulted in a decrease of P II delivery (Candide et al., 1986). Polo et al. (2002) compared the accumulation of PII by human and rat transformed fibroblasts and the inter- take. Our investigations confirm the distinction in PII uptake between different cells. The work of Fickweiler et al. (1999) revealed a difference in the cellular uptake of another photosensitizer ATMPn (9-acetoxy-2,7,12,17-tetrakis-( $\beta$-methoxyethyl)-porphycene) beetwen some cell lines. This indicates that a given cell type has its own ratio of photosensitizer uptake and clearance. This suggests that the susceptibility of different cancer lines to PDT depends on various factors, among other membrane composition. 
A very important issue resulting from these investigations is whether one can predict the efficiency of PDT and establish the optimal conditions of PDT for tumours of a given cell morphology. Further studies are needed to elucidate this problem.

\section{R E F E R E N C E S}

Biade S, Maziere JC, Mora L, Santus R, Morliere P, Maziere C, Salmon S, Gatt S, Dubertret L. (1992) Photosensitization by Photofrin II delivered to WI26VA4

SV40-transformed human fibroblasts by low density lipoproteins: inhibition of lipid synthesis and fatty acid uptake. Photochem Photobiol.; 55: 55-61.

Byrne CJ, Marschallsay LV, Ward AD. (1990) The composition of photofrin II. J Photochem Photobiol B: Biol.; 6: 13-27.

Candide C, Morliere P, Maziere JC, Goldstein S, Santus R, Dubertret L, Reyftmann JP, Polonovski J. (1986) In vitro interaction of the photoactive anticancer porphyrin derivative photofrin II with low density lipoprotein, and its delivery to cultured human fibroblasts. FEBS Lett.; 207: 133-8.

Fernandez JM, Bilgin MD, Grossweiner LI. (1997) Singlet oxygen generation by photodynamic agents. J Photochem Photobiol B: Biol.; 37: 131-40.

Fickweiler S, Abels C, Karrer S, Bäumler W, Landthaler M, Hofstädter F, Szeimies R. (1999) Photosensitization of human skin cell lines by ATMPn (9-acetoxy-2,7,12,17-tetrakis( $\beta$-methoxyethyl)-porphycene) in vitro: mechanism of action. $J$ Photochem Photobiol B: Biol.; 48: 27-35.

Foster TH, Murant RS, Bryant RG, Knox RS, Gibson LS, Hlif R. (1991) Oxygen consump- tion and diffusion effects in photodynamic therapy. Radiat Res.; 126: 296-303.

Furuse K, Fukuoka M, Kato H, Horai T, Kubota K, Kodama N, Kusunoki Y, Takifuji N, Okunaka T, Konaka C, Wada H, Hayata Y. (1993) A prospective phase II study on photodynamic therapy with photofrin II for centrally located early-stage lung cancer. $J$ Clin Oncol.; 11: 1852-7.

Gèze M, Morlière P, Mazière JC, Smith KM, Santus R. (1994) Lysosomes, a key target of hydrophobic photosensitizers proposed for photochemotherapeutic applications. $J$. Photochem Photobiol B: Biol.; 20: 23-35.

Korbelik M. (1993) Cellular delivery and retention of photofrin: III. Role of plasma proteins in photosensitizer clearance from cells. Photochem Photobiol.; 57: 846-50.

Kriska T, Korecz Ł, Nemes I, Gal D. (1995) Physico-chemical modeling of the role of free radicals in photodynamic therapy. III. Interactions of stable free radicals with excited photosensitizers studied by kinetic ESR spectroscopy. Biochem Biophys Res Commun.; 215: 192-8.

Ochsner M. (1997) Photophysical and photobiological processes in the photodynamic therapy of tumors. $J$ Photochem Photobiol B: Biol.; 39: 1-18.

Polo L, Valduga G, Jori G, Reddi E. (2002) Low-density lipoprotein receptors in the uptake of tumour photosensitizers by human and rat transformed fibroblasts. Int $J$ Biochem Cell Biol.; 34: 10-23.

Ricchelli F. (1995) Photophysical properties of porphyrins in biological membranes. $J$ Photochem Photobiol B: Biol.; 29: 109-18.

Sternberg ED, Dolphin D, Bruckner Ch. (1998) Porphyrin-based photosensitizers for use in photodynamic therapy. Tetrahedron.; 54: 4151-202. 